\title{
Neuroprotective effects of vitamin D on high fat diet- and palmitic acid-induced enteric neuronal loss in mice
}

Sara Larsson ${ }^{1}$ and Ulrikke Voss ${ }^{2^{*}}$ (D)

\begin{abstract}
Background: The role of vitamin D in obesity and diabetes is debated. Obese and/or diabetic patients have elevated levels of free fatty acids, increased susceptibility to gastrointestinal symptoms and are suggested to have altered vitamin D balance. The enteric nervous system is pivotal in regulating gastrointestinal activity and high fat diet (HFD) has been shown to cause loss of enteric neurons in ileum and colon. This study investigates the effect of vitamin D on HFD- and palmitic acid-induced enteric neuronal loss in vivo and in vitro.

Methods: Mice were fed either a normal diet (ND) or HFD supplemented with varying levels of vitamin D (from 0x to 20x normal vitamin D level) for 19 weeks. lleum and colon were analyzed for neuronal numbers and remodeling. Primary cultures of myenteric neurons from mouse small intestine were treated with palmitic acid $\left(4 \times 10^{-4} \mathrm{M}\right)$ and/or

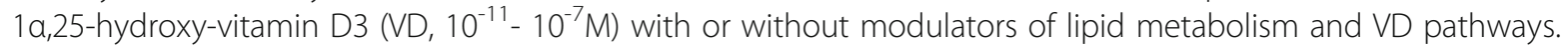
Cultures were analyzed by immunocyto- and histochemical methods.

Results: Vitamin D supplementation had no effect on enteric neuronal survival in the ND group. HFD caused substantial loss of myenteric neurons in ileum and colon. Vitamin D supplementation between 0-2x normal had no effect on HFD-induced neuronal loss. Supplementation with 20x normal, prevented the HFD-induced neuronal loss. In vitro supplementation of VD prevented the palmitic acid-induced neuronal loss. The VD receptor (VDR) was not identified in enteric neurons. Enteric glia expressed the alternative VD receptor, protein disulphide isomerase family A member 3 (PDIA3), but PDIA3 was not found to mediate the VD response in vitro. Inhibition of peroxisome proliferator-activated receptor gamma (PPARY) and immune neutralization of isocitrate lyase prevented the VD mediated neuroprotection to palmitic acid exposure.
\end{abstract}

Conclusions: Results show that VD protect enteric neurons against HFD and palmitic acid induced neuronal loss. The mechanism behind is suggested to be through activation of PPARY leading to improved neuronal peroxisome function and metabolism of neuronal lipid intermediates.

Keywords: Enteric nervous system, Vitamin D, High fat diet, Neuronal survival, Gastrointestinal tract, Peroxisome proliferator-activated receptor gamma

\footnotetext{
* Correspondence: ulrikke.voss@med.lu.se

${ }^{2}$ Unit of Neurogastroenterology, Department of Experimental Medical

Science, Lund University, Sölvegatan 19, BMC B11, 22184 Lund, Sweden

Full list of author information is available at the end of the article
}

(c) The Author(s). 2018 Open Access This article is distributed under the terms of the Creative Commons Attribution 4.0 International License (http://creativecommons.org/licenses/by/4.0/), which permits unrestricted use, distribution, and reproduction in any medium, provided you give appropriate credit to the original author(s) and the source, provide a link to the Creative Commons license, and indicate if changes were made. The Creative Commons Public Domain Dedication waiver (http://creativecommons.org/publicdomain/zero/1.0/) applies to the data made available in this article, unless otherwise stated. 


\section{Background}

The role of vitamin D has expanded beyond its classical role in calcium homeostasis. Since animal studies have shown that vitamin $\mathrm{D}$ supplementation protects against high fat diet (HFD) induced metabolic parameters [1-3], several efforts have been made to elucidate the role of vitamin $\mathrm{D}$ in type-2 diabetes and in obesity, as well as in their complications [4-6]. Recently animal models have likewise shown that various dietary vitamin D supplementations are able to protect against neurodegeneration found in i.e. models of Alzheimer's disease [7, 8]. While the clinical data on vitamin D supplementation are inconclusive $[9,10]$, the need for exploring the metabolic potential and cellular mechanisms of vitamin D remains.

Whether produced in the skin through UV radiation or ingested in the diet, vitamin D (25-hydroxy vitamin D3) is in the body converted to its active form $1 \alpha, 25$-hydroxy-vitamin D3 (VD), by the enzyme $1 \alpha$-hydroxylase also known as cytochrome P450. This enzyme is found mainly in the kidneys but other cells types including immune cells and neurons have been shown to express this enzyme $[11,12]$. VD mediates the majority of its effects by binding to, and thereby activating the nuclear VD receptor (VDR). Upon activation, VDR dimerizes with the retinoid-X receptor (RXR) forming a heterodimer, that in turn binds to specific VD response elements (VDREs). [13, 14] However, it is suggested that initiation of VDR mediated responses cannot account for the fast responses seen upon VD stimulation in certain cell types e.g. osteoblasts and intestinal epithelial cells. [15-17] Protein disulphide isomerase family A member 3 (PDIA3), also known as 1,25MAARS, has been suggested as an alternative VD receptor, capable of mediating the fast VD responses and acting as a modulator of cellular function independent of VDR $[15,18]$. Besides the receptor mediated VD responses VD, per se, has been suggested to act as an antioxidant preventing lipid peroxidation and stabilizing cell membranes [19]. The anti-oxidative potential of $\mathrm{VD}$, independent of either VDR or PDIA3, still needs to be further assessed. In addition, VD is reported to decrease reactive oxygen species (ROS) by increasing levels of the key anti-oxidative enzymes superoxide dismutase (SOD), catalase and glutathione (GSH) [20-22].

Peripheral neuropathy is a common complication of diabetes suggested to be caused by the combination of abnormal blood glucose and lipid levels, oxidative and inflammatory stress and accumulation of advanced glycation products (AGE) [23, 24]. VD deficiency is suggested to be involved in the development of diabetic neuropathy [25]. Further, it is increasingly recognized that obesity and HFD models also are associated with a neurotoxic phenotype. In animals HFD induces anxiety-like behavior and neuronal loss in hippocampus
$[26,27]$, as well as loss of neurons in all parts of the gastrointestinal (GI) tract [28-30]. Clinical data indirectly support these findings as both depression and GI dysfunction are common comorbidities of obesity and the metabolic syndrome [31-33]. The enteric nervous system (ENS), innervates the entire GI tract and is pivotal in the regulation of all GI functions, including motility, secretion and blood flow [34]. The HFD-induced neuronal loss has been suggested to be mediated mainly by the saturated fatty acid palmitic acid (PA) and involve increased oxidative stress and derangement of metabolic pathways [28]. The aim of this study was to investigate effects of VD on HFD-induced neuronal loss and to assess possible pathways by which VD mediates it effects on PA-induced enteric neuronal loss in vitro.

\section{Methods}

In vivo experiments

C57BL/6J mice ( $n=42$, Taconic Bioscience) aged 4 weeks were randomized divided into seven groups ( $n=6$ each group), animals were housed in groups. Three groups received normal diet (ND) with different doses of Vitamin D (no vitamin D, ND 0x; normal vitamin D 1.3IU/g [35], ND $1 \mathrm{x}$; twenty times vitamin D, ND 20x). Four groups received high fat diet (HFD) with different doses of vitamin D (no vitamin D, HFD 0x; normal vitamin D, HFD 1x; double vitamin D HFD 2x; twenty times the normal vitamin D, HFD 20x). All diets were purified diets (Research Diets Inc., USA) Table 1 gives nutritional overview and diet details. After 19 weeks mice were sacrificed by cervical dislocation. The GI tract from cardia to rectum was collected, opened along the mesenteric border and emptied. Segments of ileum and transverse colon were fixed and processed for cryo-sectioning [36].

Table 1 Nutritional content and vitamin D concentration in the normal diet (ND) and high fat diet (HFD)

\begin{tabular}{lll}
\hline & ND/D12450J & HFD/D12492 \\
\hline Protein & $20 \mathrm{kcal} \%$ & $20 \mathrm{kcal} \%$ \\
Carbohydrate & $70 \mathrm{kcal} \%$ & $20 \mathrm{kcal} \%$ \\
$\quad$ Sucrose & $6.8 \mathrm{kcal} \%$ & $6.8 \mathrm{kcal} \%$ \\
Fat & $10 \mathrm{kcal} \%$ & $60 \mathrm{kcal} \%$ \\
Saturated & $2 \mathrm{kcal} \%$ & $19 \mathrm{kcal} \%$ \\
Mono unsaturated & $3 \mathrm{kcal} \%$ & $22 \mathrm{kcal} \%$ \\
Poly unsaturated & $5 \mathrm{kcal} \%$ & $19 \mathrm{kcal} \%$ \\
Vitamin D & & \\
$0 x$ & - & - \\
$1 \mathrm{x}$ & $1.3 \mathrm{IU} / \mathrm{g}$ & $1.3 \mathrm{IU} / \mathrm{g}$ \\
$2 \mathrm{x}$ & - & $2.6 \mathrm{IU} / \mathrm{g}$ \\
$20 \mathrm{x}$ & $26 \mathrm{IU} / \mathrm{g}$ & $26 \mathrm{IU} / \mathrm{g}$ \\
\hline
\end{tabular}




\section{In vitro experiments}

\section{Primary enteric cultures}

C57Bl/6J mice ( $n=46,20-23 g$, Janvier Labs, FR) on standard chow diet (R36 Lactamin, SE) were used for in vitro experimentations, animals were housed in groups. Primary cultures of myenteric neurons were prepared from the small intestine. Isolation was done in the morning. Neurons were dissociated using a modification of a previously described method [28, 37]. In brief, anesthetized mice (i.p. injection with Ketalar/Rompun) had their small intestine exposed via midline incisions. The longitudinal muscle layer with attached myenteric ganglia was stripped from approximately $15 \mathrm{~cm}$ of the distal small intestine. Tissues were placed in $\mathrm{Ca}^{2+}$ and $\mathrm{Mg}^{2+}$ free Hank's balanced salt solution (HBSS) containing 1.9 collagen digestion units $(\mathrm{CDU}) / \mathrm{mL}$ collagenase 1 -A $(1.5$ $\mathrm{mg} / \mathrm{mL}$, Merck, SE) and $4.7 \mu \mathrm{U} / \mathrm{mL}$ protease IX $(1.5 \mathrm{mg} /$ $\mathrm{mL}$, Sigma-Aldrich, SE) and enzymatically and mechanically separated. Trypsin $(0.4 \mathrm{mg} / \mathrm{mL}$, BioChrom AG) and EDTA (0.003\%; Merck) were added. Trypsin was inactivated by addition of $50 \% \mathrm{v} / \mathrm{v}$ fetal bovine serum (FBS, Biowest, FR). Cell suspension was centrifuged at $15.6 \mathrm{~g}$ for $10 \mathrm{~min}$. Supernatant was removed and pellet washed three times in HBSS, centrifuged at $15.6 \mathrm{~g}$ for 10 min and diluted to $0.8 \mathrm{~mL}$ in Neurobasal A (NBA) cell culture medium (ThermoFisher Scientific, SE) containing 10\% FBS (Biowest, FR), 0.5 mM L-glutamine (K0282, BioChrom AG), $50 \mathrm{U} / \mathrm{mL}$ penicillin and $50 \mu \mathrm{g} / \mathrm{mL}$ streptomycin (A2213, BioChrom AG). Cell cultures were prepared by adding $50 \mu \mathrm{L}$ of the constantly mixed cell suspension into 8-well chambers (30108, SPL, Saveen Werner) prefilled with $450 \mu \mathrm{L}$ of the NBA cell culture medium. From each animal two 8-well chambers $\left(69 \mathrm{~mm}^{2} /\right.$ well) were prepared. Suspensions from multiple animals were never pooled. Cultures were incubated 4 days prior to experimental treatments.

\section{Experimental treatment agents}

Stock solutions of palmitic acid (PA, P9767, Merck), VD (D1530, Merck), 7-dihydrocholesterol (7DHC), 16F16 (SML0021 Merck, PDIA3 inhibitor [38]), GW69662 (M6191, Merck, peroxisome proliferator-activated receptor gamma (PPAR $\gamma$ ) inhibitor [28]), were prepared, aliquoted and stored at $-20{ }^{\circ} \mathrm{C}$. Isocitrate lyase (ICL) antibody (AS10713, Agrisera, SE) and pre-immunization sera (AS03 027, Agrisera, SE) were aliquoted and stored at $4{ }^{\circ} \mathrm{C}$.

\section{Experimental set ups}

Various sets of experiments were performed. 1. Cultures were exposed to medium containing either $\mathrm{PA}\left(4 \times 10^{-4} \mathrm{M}\right)$, VD $\quad\left(10^{-11}-10^{-7} \mathrm{M}\right), \quad 7 \mathrm{DHC} \quad\left(10^{-11}-10^{-7} \mathrm{M}\right), \quad 16 \mathrm{~F} 16$ $\left(7 \times 10^{-8}-2 \times 10^{-5} \mathrm{M}\right), \quad$ GW69662 $\left(10^{-6} \mathrm{M}\right)$, ICL antibody (1:250) or pre-immunization sera (1:250). 2 Cultures were exposed to either VD $\left(10^{-11}-10^{-7} \mathrm{M}\right)+\mathrm{PA}$ $\left(4 \times 10^{-4} \mathrm{M}\right)$ or $7 \mathrm{DHC}\left(10^{-9}-10^{-7} \mathrm{M}\right)+\mathrm{PA}\left(4 \times 10^{-4} \mathrm{M}\right) .3$. Cultures were exposed to either VD $\left(10^{-7} \mathrm{M}\right)+$ experimental treatment agent, $\mathrm{PA}\left(4 \times 10^{-4} \mathrm{M}\right)+$ experimental treatment agent or VD $\left(10^{-7} \mathrm{M}\right)+\mathrm{PA}\left(4 \times 10^{-4} \mathrm{M}\right)+$ experimental treatment agent. Cultures were incubated 4 days in treatment media with controls run in parallel, fixated in Stefaninins and processed for immunocytochemistry.

\section{Histology and immunocytochemistry}

For details on primary and secondary antibodies see Table 2. All antibodies were diluted in phosphate buffered saline (PBS) containing $0.25 \%$ Triton X-100 and $0.25 \%$ BSA (PBS-T-B). For visualization of submucous and myenteric neurons, cryo-sections from ND and $\mathrm{HFD}$ mice were immunolabeled with $\mathrm{HuC} / \mathrm{HuD}$-biotin and vectastain $\mathrm{ABC}$ kit (Vector laboratories Inc., USA), according to manufacturer's protocol [28, 39]. Morphometric analyses of intestines were on Toluidine blue ( $0.01 \%$ in $60 \%$ ethanol for $1.5 \mathrm{~min})$ stained cryo-sections.

Double immunolabeling of cultures were by overnight incubation in moist chamber at $4^{\circ} \mathrm{C}$ with a mixture of primary antibodies. Secondary antibodies were mixed and incubated $1 \mathrm{~h}$ at RT. Hoechst (ThermoFisher Scientific, SE) cell nuclei counter staining was performed according to manufacturer's protocol. Mounting was in PBS:glycerol 1:1 followed by fluorescence microscopy (Olympus BX43, LRI, SE) with appropriate filter setting.

\section{Analyses}

Mucosa and muscularis propria thicknesses were estimated for each mouse using the mean from ten measurements (Aperio ScanScope CS/GL SS5082 and ImageScope). The numbers of $\mathrm{HuC} / \mathrm{HuD}$-immunoreactive submucous and myenteric neuronal cell bodies were counted per $\mathrm{mm}$ section length. From each mouse, cryo-sections $(10 \mu \mathrm{m})$ cut longitudinally at 3-4 different depths comprising a total length of $30-50 \mathrm{~mm}$, were used. Analyses were done blinded to treatment.

Neuronal survival was estimated according to previously described protocol [28, 37]. In brief, neuronal survival after exposure to the various treatments was calculated by counting the total number of $\mathrm{HuC} / \mathrm{HuD}$-immunoreactive (IR) neurons in the entire culture well $\left(69 \mathrm{~mm}^{2}\right)$ and expressed as percentage of the number of total neurons in the control well run in parallel (\% neuronal survival of control). With a minimum of 6 observations in 3 biological repeats, in each treatment group.

Data are presented as means \pm SEM and analyzed by GraphPad Prism (GraphPad Software Inc, USA). Statistical significance was determined using two-way analysis of variance followed by Bonferronis post hoc test (in vivo data), or one-way analysis of variance followed by Dunnet's post hoc test towards controls (in vitro data). A confidence interval of $95 \%$ was considered significant. 
Table 2 Overview of primary and secondary antibodies used in immunocytochemistry

\begin{tabular}{|c|c|c|c|c|c|}
\hline Raised against & Dilution & Code & Source & Host & References \\
\hline Human neuronal protein, (HuC/HuD) & $1: 600$ & A21272 & ThermoFisher Scientific, SE & Mouse & {$[37,73]$} \\
\hline Human gene product 9.5, (PGP 9.5), purified human brain & $1: 1.200$ & RA95101 & Ultraclone, UK & Rabbit & [73] \\
\hline PDIA3 & 1:500 & AF8219 & R\&D systems, USA & sheep & \\
\hline VDR & $1: 400$ & Sc-13133 & Kind gift professor BO Nilsson, Lund & Mouse & [74] \\
\hline S100B (S100), purified bovine brain & 1:12.000 & Z0311 & DAKO, DK & Rabbit & [75] \\
\hline Alexa Fluor 488 anti-mouse $\lg G$ & $1: 1.000$ & $115-485-166$ & Jackson Lab Inc, USA & Goat & \\
\hline Dy-light 594 anti-mouse $\lg G$ & 1:1.000 & $715-515-151$ & Jackson Lab Inc, USA & Donkey & \\
\hline Alexa Fluor 594 anti- rabbit $\lg G$ & $1: 1.000$ & $711-515-152$ & Jackson Lab Inc, USA & Donkey & \\
\hline Alexa Fluor 488 anti goat lgG & $1: 1000$ & $705-545-147$ & Jackson Lab Inc, USA & donkey & \\
\hline Texas Red anti goat lgG & $1: 400$ & 705-075-147 & Jackson Lab Inc, USA & donkey & \\
\hline
\end{tabular}

\section{Results}

\section{In vivo}

All animals were included in the study. Morphometric analyses of muscularis propria and mucosa in ileum (Fig. 1d) and colon (Fig. 1g) revealed no effect of dietary vitamin D supplementation on intestinal morphology. A slight thickening $(\mathrm{p}<0.05)$ of ileum muscularis propria in the HFD 0x group was observed compared to the ND $1 \mathrm{x}$ group (Fig. 1d). None of the dietary vitamin D supplementations affected neuronal survival in either ileum (Fig. 1e, f) or colon (Fig. 1h, i) in animals fed the ND. HFD is known to induce loss of myenteric, but not submucosal, enteric neurons in mice [28, 30, 40]. Vitamin D supplementation in the $0-2 x$ range did not attenuate the HFD induced enteric neuronal loss, in ileum (Fig. 1e, f) or colon (Fig. 1h, i). However, animals receiving 20x the normal vitamin $\mathrm{D}$ concentration were protected against the HFD-induced neuronal loss in both ileum (Fig. 1e, f) and colon (Fig. 1h, i).

\section{In vitro, VD effects on primary enteric cultures}

Primary cultures isolated from the longitudinal muscle layer of mouse small intestine contains myenteric ganglia, glia and smooth muscle cells, effects of PA exposure on these has previously been described [28]. Control wells displayed $2.2 \pm 0.1$ neurons per $\mathrm{mm}^{2}$. Exposure to VD $\left(10^{-11}-10^{-7} \mathrm{M}\right)$ per se did not affect neuronal survival in cultures (Fig. 2a). VD serum concentration in mice are suggested to be in the $10^{-10} \mathrm{M}$ range [41]. Palmitic acid exposure alone induced a significant loss of cultured neurons $(p<0.01$, Fig. $2 b)$, the loss was similar in magnitude to the previous described PA induced loss [28]. The combined exposure of PA $\left(4 \times 10^{-4} \mathrm{M}\right)$ and VD $\left(10^{-11}-10^{-7} \mathrm{M}\right)$ did not affect neuronal survival (Fig. 2b). Thus, the presence of VD $\left(10^{-11}-10^{-7} \mathrm{M}\right)$ abolished the previous described PA-induced neuronal loss. To test if the effect was due to the activated form of vitamin $D$ $(1 \alpha, 25$-hydroxy-vitamin D3, VD) cultures were exposed to the vitamin $\mathrm{D}$ precursor 7-dihydrocholesterol (7DHC). Exposure of $7 \mathrm{DHC}\left(10^{-11}-10^{-7} \mathrm{M}\right)$ per se didn't affect neuronal survival (Fig. 2c). Addition of $7 \mathrm{DHC}\left(10^{-9}-10^{-7} \mathrm{M}\right)$ was unable to protect enteric neurons against the PA-induced neuronal loss (Fig. 2b).

\section{Localization of VDR and PDIA3 in vivo and in vitro}

Immunocytochemistry revealed VDR expression in mucosal epithelial cells of both small and large intestine while no VDR expression was detected in enteric neurons in vivo regardless of diet. In primary cultures of enteric neurons, no VDR expression was found in neurons. The alternative vitamin $\mathrm{D}$ receptor PDIA3 has been suggested to mediate the rapid effects of vitamin D in intestinal epithelial cells [15]. Immunocytochemistry revealed PDIA3 not to be expressed on enteric neurons (Fig. 3a-f) in vivo or in vitro, but to be expressed in intestinal glia in close connection to enteric neurons (Fig. 3g-i). This was evident in enteric neuronal cultures as well (Fig. 3j-1).

\section{In vitro inhibition of PDIA3 in primary enteric cultures}

To evaluate if the VD effect was acting indirect by way of PDIA3 activation in enteric glia, primary enteric cultures were exposed to 16F16, known to inhibit PDI's including PDIA3 [38]. The inhibitor $\left(7 \times 10^{-8} \mathrm{M}-2 \times 10^{-5} \mathrm{M}\right)$ induced neuronal loss at concentrations above $7 \times 10^{-7}$, with all cells in culture lost at $2 \times 10^{-5} \mathrm{M}$ (Fig. 4a). Supplementation with the PDIA3 inhibitor $\left(10^{-7} \mathrm{M}\right)$ did not affect PA-induced neuronal loss in vitro nor did supplementation prevent the VD-mediated protection of the PA-induced neuronal loss. However, supplementation with the PDIA3 inhibitor $\left(10^{-7} \mathrm{M}\right)$ significantly reduced neuronal survival in VD treated cultures (Fig. 4b).

\section{In vitro inhibition of PPARY in primary enteric cultures}

VDR is, like peroxisome proliferator-activated receptor (PPAR), a member of the nuclear hormone receptor family that form heterodimers with RXR. VDR and PPAR have interacting signaling pathways [42]. Primary enteric cultures were supplemented with the PPAR $\gamma$ inhibitor GW9662 $\left(10^{-6} \mathrm{M}\right)$. The effect of GW9662 on cultured enteric neurons and glia, has been assessed in a 


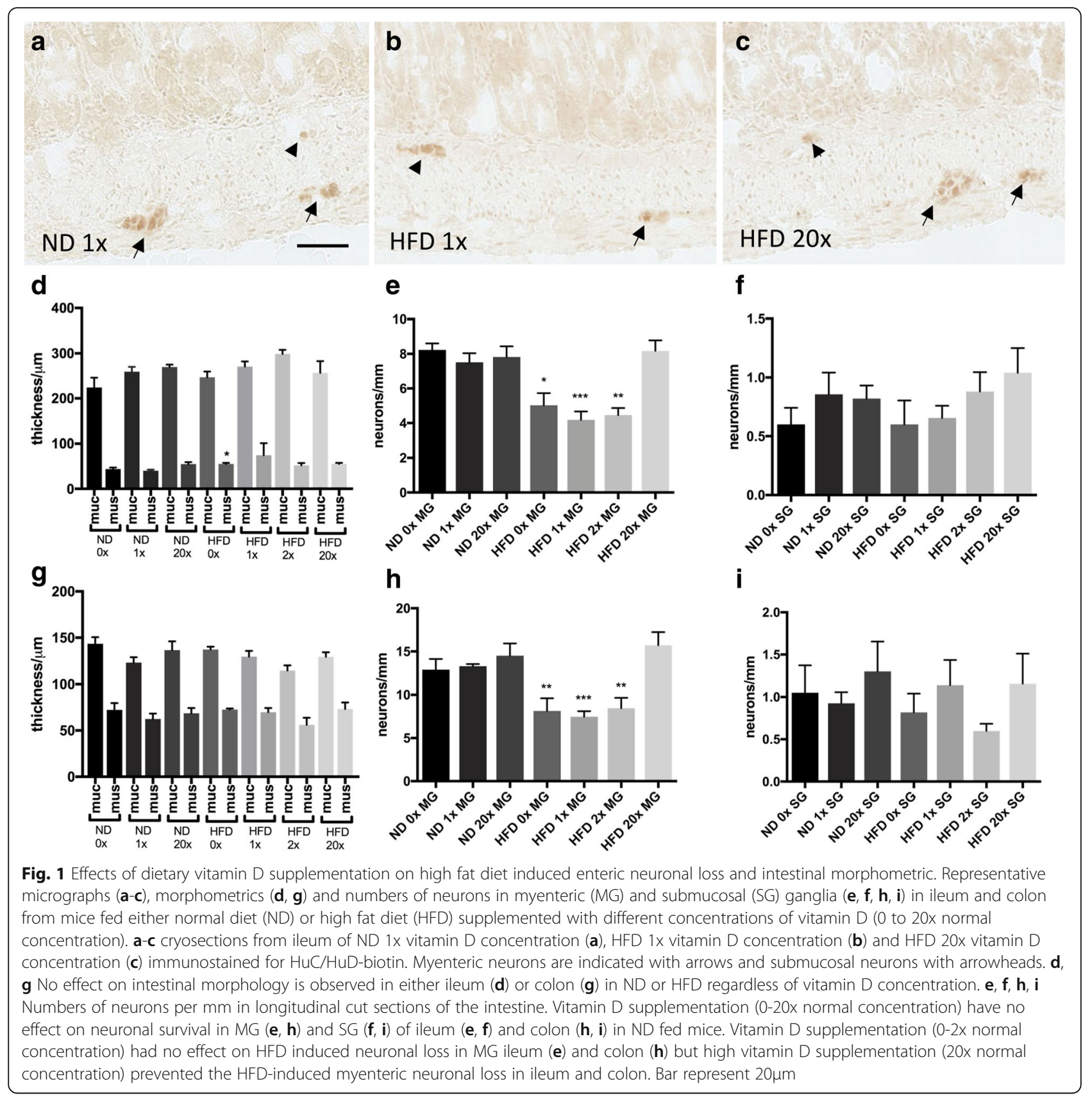

previous study [28]. Supplementation of the PPARY inhibitor did not prevent the PA induced neuronal loss, but did prevent the VD-mediated protection of the PA-induced neuronal loss (Fig. 4c).

\section{In vitro ICL antibody neutralization}

Bacteria, fungi and plants use the glyoxylate cycle to bypass the $\mathrm{CO}_{2}$ producing step in the Krebs cycle, utilizing two enzymes, ICL and malate synthase. Exposing enteric neuronal cultures to pre-immune serum (1:250) did not affect neuronal survival per se or VD's effect on PA-induced neuronal loss (Fig. 4d). Exposing cultures to
ICL immune sera (1:250) did not affect neuronal survival per se nor the PA-induced neuronal loss. However, ICL immune sera supplementation prevented the protective effect of vitamin D on PA-induced neuronal loss (Fig. 4e).

\section{Discussion}

Current study investigated the neuroprotective potential of vitamin D and VD on HFD- and PA-induced enteric neuronal loss. Vitamin D supplementation with $1.3 \mathrm{IU} / \mathrm{g}$ to $2.6 \mathrm{IU} / \mathrm{g}$ had no effect on either ND or HFD enteric neuronal survival. However, supplementation of vitamin $\mathrm{D}$ at $26 \mathrm{IU} / \mathrm{g}(20 \mathrm{x})$ prevented the HFD-induced neuronal 


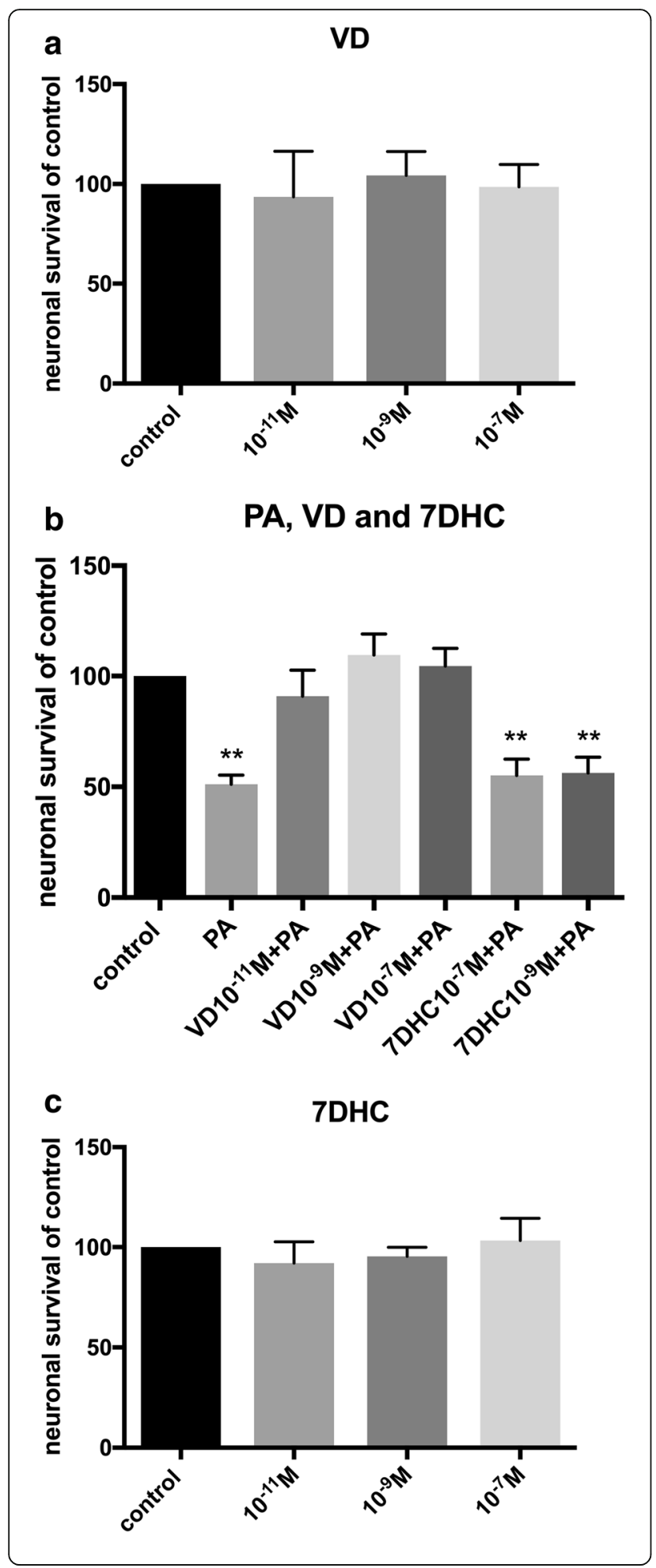

Fig. 2 Effects of PA, VD and 7DHC in primary cultures of enteric neurons. a, c Supplementation with 1a,25-hydroxy-vitamin D3 (VD, $\left.10^{-11}-10^{-7} \mathrm{M}\right)$ or 7 -dihydrocholesterol (7DHC $\left.10^{-11}-10^{-7} \mathrm{M}\right)$ had no effect on neuronal survival. b Cultures treated with palmitic acid (PA, $4 \times 10^{-4} \mathrm{M}$ ) induced enteric neuronal loss, supplementation with VD but not 7DHC prevented the PA induced loss. Untreated controls were run in parallel. Data presented as mean \pm SEM, per treatment group, control $n=6-12$ per group, palmitic acid (PA) $n=6$, VD $n=6-12$, $7 \mathrm{DHC}, \mathrm{PA}\left(4 \times 10^{-4} \mathrm{M}\right)+\mathrm{VD}\left(10^{-11}-10^{-7} \mathrm{M}\right) n=6, \mathrm{PA}\left(4 \times 10^{-4} \mathrm{M}\right)+7 \mathrm{DHC}$ $\left(10^{-9}-10^{-7} \mathrm{M}\right) n=6,{ }^{* *} p<0.01$

loss, without affecting ND neuronal survival. In vitro studies showed VD $\left(10^{-11} \mathrm{M}-10^{-7} \mathrm{M}\right)$ to protect against PA-induced neuronal loss, this effect was due to the presence of $\mathrm{VD}$ as the biological inactive precursor 7HDC was unable to mimic this neuroprotective effect. Serum concentration of VD were not assessed in current study. However, it has been demonstrated that supplementation of 10x the normal vitamin $\mathrm{D}$ dose in mice does not lead to elevated serum VD levels $\left(10^{-10} \mathrm{M}\right)$ nor induce hypercalcemia [41]. It is therefore not believed that supplementing with 20 times the normal dose would lead to toxicity. Further it has been shown that obesity is associated with lower vitamin D serum concentration, and patients should increase daily vitamin D intake [43].

\section{HFD- and PA-induced neurotoxicity}

VD is a lipid soluble vitamin and adipocytes function as an important VD reservoir [44]. With the obesity epidemic and subsequent increase in type 2-diabetes [45], together with data suggesting that VD deficiency is a global health problem among all age groups [46], it is not surprising that the ability of VD to interfere with metabolic pathways have especially been studied in adipocytes and liver. In adipocytes, VD is involved in the regulation of differentiation, apoptosis, lipogenesis as well as acting as an anti-inflammatory agent [2, 47]. In liver, VD has experimentally been shown to be protective in HFD-induced steatosis. This is suggested to be through modulation of lipid metabolism, by increasing expression of enzymes and transcription factors involved in fatty acid oxidation i.e. carnitine-palmitoyl transferase 1a and $1 \mathrm{~b}(\mathrm{CPT} 1 \mathrm{a}, \mathrm{b})$, pyruvate dehydrogenase kinase 4 (PDK4) and PPAR $1 \alpha .[1-3,48]$ While studies have shown neurons capable of both mitochondrial and peroxisomal fatty acid oxidation [49], they are not believed to rely on lipids for energy production [50], this is seen by e.g. their low expression of CPT1a and CPT1b in mitochondrial membranes and their expression of CPT1c on endoplasmic reticulum (ER) membranes [51, 52]. HFD- and PA-induced enteric neuronal losses have been investigated previously $[28,29]$. Using pharmacological agents interfering with intracellular lipid handling 


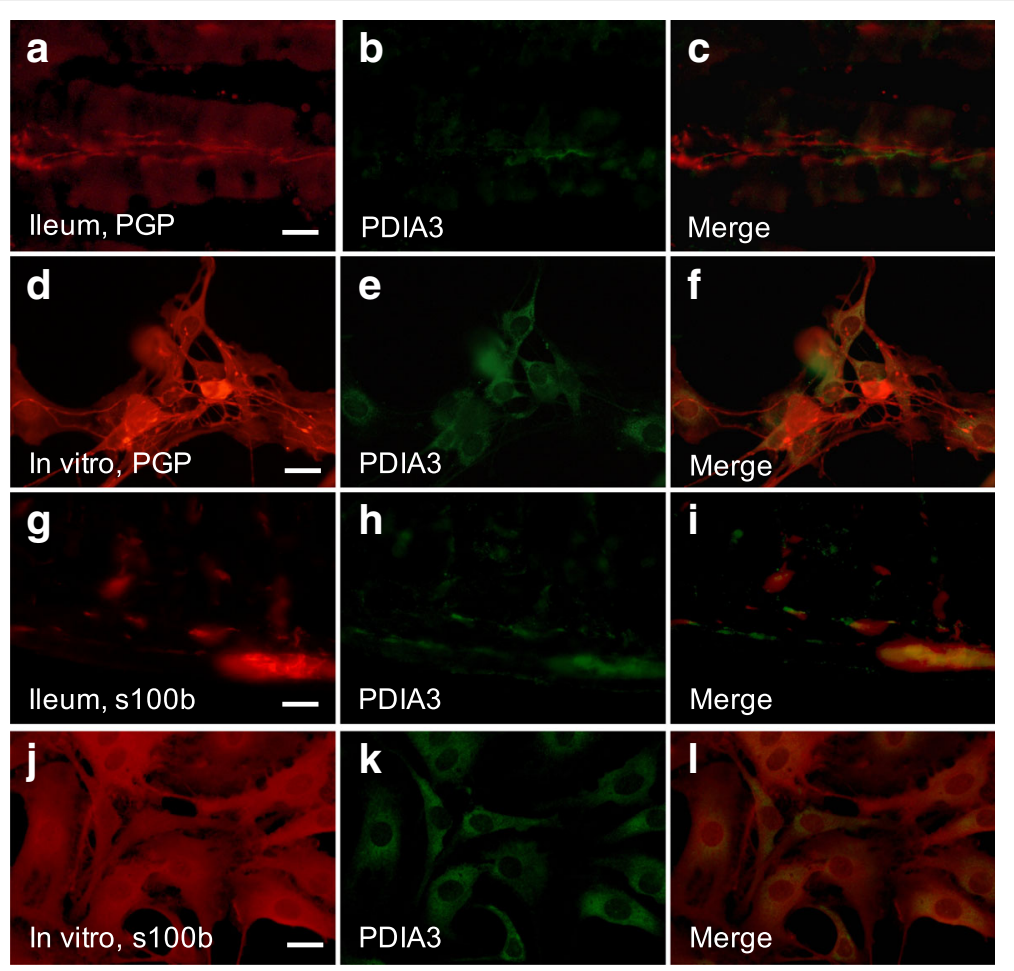

Fig. 3 Localisation of PDIA3 in mouse and primary cultures of myenteric neurons. Representative micrographs of ileum of normal diet $1 x$ vitamin $\mathrm{D}$ animals $(\mathbf{a}-\mathbf{c}, \mathbf{g}-\mathbf{i})$ and of primary cultures myenteric neurons $(\mathbf{d}-\mathbf{f}, \mathbf{j}-\mathbf{-})$. $\mathbf{a}-\mathbf{f}$ Immunocytochemical staining of neuronal cell bodies and fibres using PGP9.5 in ileum (a) and culture (d) and PDIA3 positive fibres and cell bodies in ileum (b) and culture (e), merged images showing PDIA3 is not co-located with enteric neurons in ileum (c) and culture (f). $\mathbf{g}$-i Immunocytochemical staining to enteric glia using S100 $\beta$ in ileum (g) and culture (j) and PDIA3 positive fibres and cell bodies in ileum (h) and culture (k), merged images show co-localisation of S100 $\beta$ and PDIA3, suggesting PDIA3 is expressed in enteric glia. Bars represent $20 \mu \mathrm{m}$

pathways it was suggested that PA-induced neuronal loss in vitro was through the culmination of multiple metabolic disturbances. This Includes excessive palmitoylcarnitine formation, exhausted carnitine stores, increased acetate-coenzyme A (-CoA) levels and energy depletion as well as increased levels of oxidative stress and membrane destabilization [28]. The ability of VD to interfere with these metabolic pathways was, in current study, tested in vitro.

\section{Receptor mediated VD effects}

VD classically mediates its responses by binding to the nuclear VDR, leading to altered gene transcription, VDRs have also been found in plasma membranes, co-localized with caveolin 1 , where they are suggested to mediate a fast response [53]. Upon activation VDR forms homodimers with RXR and these complexes modulate gene expression through binding to VDREs [13, 14]. In man more than 2700 genes have been identified to be regulated by VDR [14]. By immunocytochemistry VDR was not found in enteric neurons either in vivo or in vitro. It should, in this regard be noted that muscle cells (cardiac, skeletal and smooth) display positive VD mediated effects without clear evidence of the VDR being present [54]. It has been suggested that the non-genomic rapid effect of VD is through activation of the alternative VD receptor, PDIA3 [15]. PDIA3 has been ascribed pleiotropic effects, including reduction of cellular stress in neurons $[55,56]$, protection against autophagy induced apoptosis in beta cells [57], and protection against free fatty acid induced hepatosteatosis [58]. Immunocytochemistry showed PDIA3 to be found in enteric glia in vivo and in vitro. Enteric glia play important roles in the gut including acting as neuronal support and protection [59]. Inhibiting PDIA3 in vitro did not prevent the ability of VD to protect enteric neurons against PA-induced loss. This suggests that VD does not mediate its neuroprotective effect through activation of PDIA3 in enteric glia.

\section{Oxidative stress and membrane destabilization}

VD mediates anti-inflammatory effects and has been shown to reduce HFD-induced increases in tumor necrosis factor $\alpha(\mathrm{TNF} \alpha)$ and pro-inflammatory cytokines such as interleukin (IL) -6 and lipid peroxidation products [60,61]. Besides anti-inflammatory effects VD has also been shown to have anti-oxidative effects by expression of anti-oxidative enzymes such as superoxide dismutase (SOD), glutathione (GSH), and catalase [21, 22]. 
a

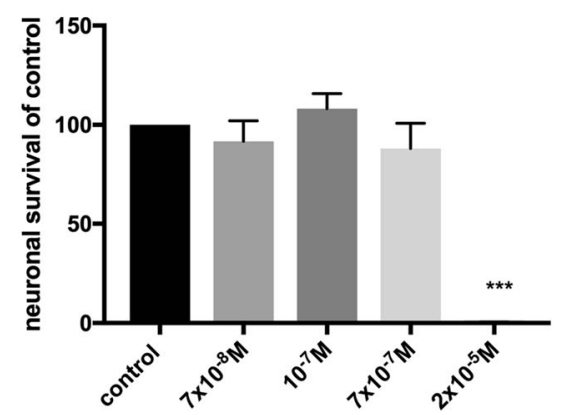

C

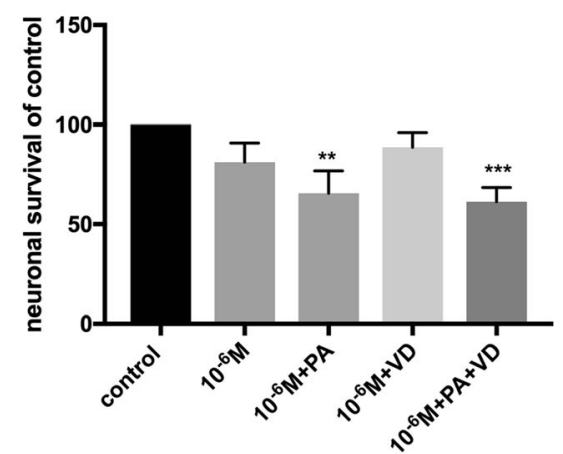

e

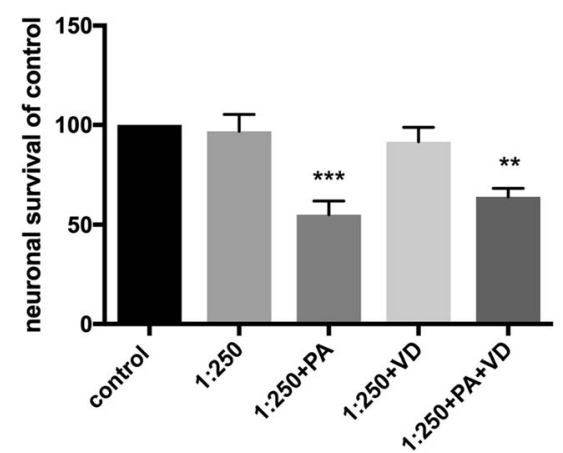

b

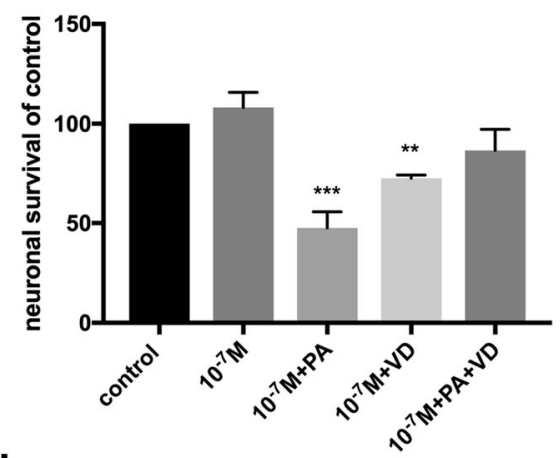

d

Pre-immune sera

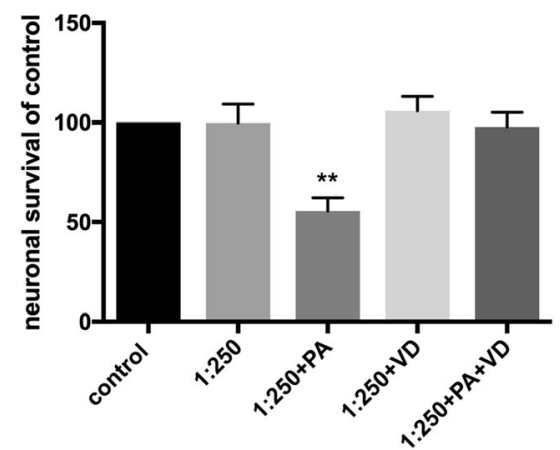

Fig. 4 Effects of experimental treatment agent per se and on VD and VD+PA neuronal survival and PA-induced neuronal loss in primary cultures of myenteric neurons. a Supplementation with the protein disulphide isomerase family A member 3 (PDIA3) inhibitor $16 \mathrm{~F} 16$ in the range $7 \times 10^{-8} \mathrm{M}-7 \times 10^{-7} \mathrm{M}$ did not affect neuronal survival, but induced loss of all cells at $2 \times 10^{-5} \mathrm{M}$. b Supplementation with the PDIA3 inhibitor (10 $\left.0^{-7} \mathrm{M}\right)$ had no effect on the palmitic acid $\left(P A, 4 \times 10^{-4} \mathrm{M}\right)$, the 1a,25-hydroxy-vitamin $\mathrm{D} 3\left(\mathrm{VD}, 10^{-7} \mathrm{M}\right)$ or the PA+VD effects on neuronal survival. $\mathbf{c}$ Peroxisome proliferator-activated receptor gamma (PPARY) inhibitor, GW69662 (10-6 M) did not prevent the PA-induced neuronal loss but prevented the VD-induced prevention of the

PA-induced loss. d Supplementation with pre-immune sera (1:250) had no effects on PA-, VD- or PA+VD-induced effects on neuronal survival. e Supplementation of isocitrate lyase (ICL) immune sera (1:250) did not prevent the PA-induced loss but did prevent the protective effects of VD on PA-induced loss. Untreated controls were run in parallel. Data presented as mean \pm SEM, control $n=6-18$ per treatment agent, PDIA3 inhibitor $16 F 16$ $n=6-12$, PPARY inhibitor, GW69662 $n=6$, pre-immune sera $n=6$, ICL immune sera $n=6$, PDIA3 inhibitor $\left(10^{-7} \mathrm{M}\right)+$ PANDND+PA $n=6$, PPARY inhibitor (10 $\left.0^{-6} \mathrm{M}\right)$ + PANDND+PA $n=6-12$, pre immune sera $(1: 250) n=12$, ICL immune sera $(1: 250) n=12-18$, ${ }^{* *} p<0.01,{ }^{* * *} p<0.001$

However, VD has also been shown, independent of receptor activation, to act as a membrane antioxidant by inhibiting lipid peroxidation. In the study, authors found the precursor $7 \mathrm{HDC}$ to be a more potent antioxidant than VD [19]. While current results showed 7HDC unable to prevent PA-induced neuronal loss, a direct anti-oxidative effect of VD in the protection against PA-induced loss cannot be entirely excluded.

\section{Energy metabolism}

HFD disrupts the energy balance and pushes the system towards a more inflammatory and reactive oxygen 
species-rich phenotype. VD has been suggested to modulate energy pathways, including upregulating genes involved with fatty acid oxidation and anti-oxidation [3]. HFD has been shown to cause a reduced PPARy expression and classical PPAR $\gamma$ targets including CD36 in neurons [62], as well as in the small intestine [63]. In neurons PPAR $\gamma$ was suggested to act as neuronal lipid sensor, sensing and signaling to the central nervous system clues about the peripheral metabolic status [62]. In the intestinal epithelial cells, PPAR $\gamma$ is suggested to regulate barrier function and microbiome related inflammation [63]. We show that inhibition of PPARY prevents the VD induced protection against the PA-induced neuronal loss in vitro, suggesting that high VD concentrations induce PPARy activity.

\section{Alternative VD pathway}

Plants, bacteria and nematodes have maintained the ability to synthesize glucose from lipids, using acetate produced from peroxisomal beta oxidation. This energy bypass is called the glyoxylate cycle. It is catalyzed by two enzymes isocitrate lyase (ICL) and malate synthase (MS) and is active in situations where environmental energy supply demands it [64]. In peroxisomes isocitrate is cleaved by ICL to form succinate and glyoxylate. Succinate enter the Krebs cycle and glyoxylate condenses with -CoA forming malate in a reaction catalyzed by MS. Malate can be converted into phosphoenolpyruvate by the enzyme phosphoenolpyruvate carboxykinase (PEPCK), and enter gluconeogenesis, thereby enabling lipid-derived carbon to be converted into glucose. The presence of this pathway in higher eukaryotes has been debated, including its presence and activity in peroxisomes of liver [65, 66], cartilage [67] and brown fat [68] as well as its absence. [69-71] Those suggesting its presence have shown that VD activate the glyoxylate or a glyoxylate-like cycle in liver and cartilage and stimulate the conversion of PA derived acetyl-CoA into glycogen $[65,67]$. It is tempting to speculate that high VD exposure in enteric neurons is able to stimulate this pathway. Using immunoneutralization to inhibit ICL activity we showed that supplementing cultures with ICL antibodies, but not pre-immune sera, prevented the VD-induced protection against the PA-induced neuronal loss. Whether the ICL immune serum contains undetermined mediators capable of inhibiting the VD response has not been investigated in currently study and cannot be excluded. It is however, interesting to note that PPARY is a known inducer of PEPCK, the enzyme enabling malate to enter gluconeogenesis. The induction of a glyoxylate or glyoxylate-like cycle has been suggested in hepatic glucose production [70, 72], where lipids increase hepatic gluconeogenesis. A working hypothesis in this respect could be that VD activates PAPR $\gamma$ and glyoxylate cycle-like pathways, causing PA or PA-CoA shunting towards peroxisome degradation, gluconeogenesis and glucose production. In all creating a, for neurons, non-toxic metabolic intermediate that enables survival in a PA overload situation.

\section{Conclusion}

In this study, we showed neuroprotective effects of VD against HFD- and PA-induced neuronal loss. The suggested pathway involves VD-induced activation of PPAR $\gamma$ which in turn improve neuronal peroxisome function and shuttling of PA-CoA. Suggesting that supplementation of vitamin $\mathrm{D}$ in the diet could protect enteric neurons against obesity-induced damage.

\begin{abstract}
Abbreviations
7DHC: 7-dihydrocholesterol; BSA: Bovine serum albumin; CDU: Collagen digestion units; -CoA: Acetyl- Coenzyme A; ENS: Enteric nervous system; ER: Endoplasmic reticulum; FBS: Fetal bovine serum; GSH: Glutathione; HBSS: Hank's balanced salt solution; HFD: High fat diet; ICL: Isocitrate lyase; IL: Interleukin; IR: Immunoreactive; NBA: Neurobasal A; ND: Normal diet; PA: Palmitic acid; PBS: Phosphate buffered saline; PDI: Protein disulphide isomerase; PDIA3: Protein disulphide isomerase family A member 3; PDK4: Pyruvate dehydrogenase kinase 4; PEPCK: Phosphoenolpyruvate carboxykinase; PPARY: Peroxisome proliferator-activated receptor gamma; ROS: Reactive oxygen species; RXR: Retinoid-X receptor; SOD: Superoxide dismutase; TNFa: Tumor necrosis factor alpha; VD: 1a,25-hydroxy-vitamin D3; VDR: VD receptor; VDREs: VD response elements
\end{abstract}

\section{Acknowledgements \\ The authors would like to thank professor Eva Ekblad for financial and laboratory support and valuable input. The intestinal specimens used in the in vivo study were kindly donated by professor Cecilia Holm who designed, supervised and financed the animal model. The authors would also like to thank Anna Themner-Persson for excellent technical assistance.}

\section{Funding}

This research was supported by grants from the Crafoord Foundation, the Royal Physiographic Foundation, the Påhlsson Foundation, the faculty of medicine Lund University, the Swedish Diabetes Foundation and the Swedish Research Council (project 11284 C. Holm).

\section{Availability of data and materials}

The datasets used and/or analysed during the current study are available from the corresponding author on reasonable request

\section{Authors' contributions}

SL designed and performed experiments, UV designed the study, analyzed the data and wrote the manuscript. All authors have read and approved the manuscript.

\section{Competing interest}

The authors declare that they have no competing interests.

\section{Ethics approval}

Experimental design, including housing, enrichment and animal welfare was approved by the animal ethics committee, Lund and Malmö, Sweden (dnr: M133-14 and dnr: M19-15).

Consent for publication

Not applicable

\section{Publisher's Note}

Springer Nature remains neutral with regard to jurisdictional claims in published maps and institutional affiliations. 


\section{Author details}

${ }^{1}$ Unit of Molecular Endocrinology, Department of Experimental Medical Science, Lund University, Sölvegatan 19, BMC C11, 22184 Lund, Sweden. ${ }^{2}$ Unit of Neurogastroenterology, Department of Experimental Medical Science, Lund University, Sölvegatan 19, BMC B11, 22184 Lund, Sweden.

Received: 12 September 2018 Accepted: 8 November 2018 Published online: 21 November 2018

\section{References}

1. Yin Y, Yu Z, Xia M, Luo X, Lu X, Ling W. Vitamin D attenuates high fat dietinduced hepatic steatosis in rats by modulating lipid metabolism. Eur J Clin Invest. 2012;42(11):1189-96.

2. Sergeev IN, Song Q. High vitamin D and calcium intakes reduce dietinduced obesity in mice by increasing adipose tissue apoptosis. Mol Nutr Food Res. 2014;58(6):1342-8.

3. Marcotorchino J, Tourniaire F, Astier J, Karkeni E, Canault M, Amiot MJ, Bendahan D, Bernard M, Martin JC, Giannesini B, et al. Vitamin D protects against diet-induced obesity by enhancing fatty acid oxidation. J Nutr Biochem. 2014;25(10):1077-83.

4. Witham MD, Nadir MA, Struthers AD. Effect of vitamin D on blood pressure: a systematic review and meta-analysis. J Hypertens. 2009;27(10):1948-54

5. Vimaleswaran KS, Berry DJ, Lu C, Tikkanen E, Pilz S, Hiraki LT, Cooper JD, Dastani Z, Li R, Houston DK, et al. Causal relationship between obesity and vitamin D status: bi-directional Mendelian randomization analysis of multiple cohorts. PLoS Med. 2013;10(2):e1001383.

6. Danik JS, Manson JE. Vitamin d and cardiovascular disease. Curr Treat Options Cardiovasc Med. 2012;14(4):414-24.

7. Garcion E, Wion-Barbot N, Montero-Menei CN, Berger F, Wion D. New clues about vitamin D functions in the nervous system. Trends Endocrinol Metab. 2002;13(3):100-5.

8. Grimm MO, Mett J, Hartmann T. The Impact of Vitamin E and Other FatSoluble Vitamins on Alzheimer's Disease. Int J Mol Sci. 2016;17:1785.

9. Wamberg L, Kampmann U, Stødkilde-Jørgensen H, Rejnmark L, Pedersen SB, Richelsen B. Effects of vitamin D supplementation on body fat accumulation, inflammation, and metabolic risk factors in obese adults with low vitamin D levels - results from a randomized trial. Eur J Intern Med. 2013;24(7):644-9.

10. Gallagher JC, Yalamanchili V, Smith LM. The effect of vitamin D supplementation on serum 25OHD in thin and obese women. J Steroid Biochem Mol Biol. 2013;136:195-200.

11. Eyles DW, Smith S, Kinobe R, Hewison M, McGrath JJ. Distribution of the vitamin $D$ receptor and 1 alpha-hydroxylase in human brain. J Chem Neuroanat. 2005;29(1):21-30.

12. Overbergh L, Decallonne B, Valckx D, Verstuyf A, Depovere J, Laureys J, Rutgeerts O, Saint-Arnaud R, Bouillon R, Mathieu C. Identification and immune regulation of 25-hydroxyvitamin D-1-alpha-hydroxylase in murine macrophages. Clin Exp Immunol. 2000;120(1):139-46.

13. Schmidt DR, Mangelsdorf DJ. Nuclear receptors of the enteric tract: guarding the frontier. Nutr Rev. 2008;66(10 Suppl 2):S88-97.

14. Ramagopalan SV, Heger A, Berlanga AJ, Maugeri NJ, Lincoln MR, Burrell A, Handunnetthi L, Handel AE, Disanto G, Orton SM, et al. A ChIP-seq defined genome-wide map of vitamin $D$ receptor binding: associations with disease and evolution. Genome Res. 2010;20(10):1352-60.

15. Nemere I, Hintze K. Novel hormone "receptors". J Cell Biochem. 2008; 103(2):401-7.

16. Doroudi M, Schwartz Z, Boyan BD. Phospholipase A2 activating protein is required for 1a,25-dihydroxyvitamin D3 dependent rapid activation of protein kinase C via Pdia3. J Steroid Biochem Mol Biol. 2012;132(1-2):48-56.

17. Wang Y, Chen J, Lee CS, Nizkorodov A, Riemenschneider K, Martin D, Hyzy S, Schwartz Z, Boyan BD. Disruption of Pdia3 gene results in bone abnormality and affects 1alpha,25-dihydroxy-vitamin D3-induced rapid activation of PKC. J Steroid Biochem Mol Biol. 2010;121(1-2):257-60.

18. Chen J, Olivares-Navarrete R, Wang Y, Herman TR, Boyan BD, Schwartz Z. Protein-disulfide isomerase-associated 3 (Pdia3) mediates the membrane response to 1,25-dihydroxyvitamin D3 in osteoblasts. J Biol Chem. 2010; 285(47):37041-50

19. Wiseman H. Vitamin D is a membrane antioxidant. Ability to inhibit irondependent lipid peroxidation in liposomes compared to cholesterol, ergosterol and tamoxifen and relevance to anticancer action. FEBS Lett. 1993;326(1-3):285-8.
20. Farhangi MA, Nameni G, Hajiluian G, Mesgari-Abbasi M. Cardiac tissue oxidative stress and inflammation after vitamin D administrations in high fat- diet induced obese rats. BMC Cardiovasc Disord. 2017;17(1):161.

21. Noyan T, Balaharoğlu R, Kömüroğlu U. The oxidant and antioxidant effects of 25-hydroxyvitamin D3 in liver, kidney and heart tissues of diabetic rats. Clin Exp Med. 2005;5(1):31-6.

22. Bhat $M$, Ismail A. Vitamin $D$ treatment protects against and reverses oxidative stress induced muscle proteolysis. J Steroid Biochem Mol Biol. 2015;152:171-9.

23. Singh VP, Bali A, Singh N, Jaggi AS. Advanced glycation end products and diabetic complications. Korean J Physiol Pharmacol. 2014;18(1):1-14.

24. Sandireddy R, Yerra VG, Areti A, Komirishetty P, Kumar A. Neuroinflammation and oxidative stress in diabetic neuropathy: futuristic strategies based on these targets. Int J Endocrinol. 2014;2014:674987.

25. Lv WS, Zhao WJ, Gong SL, Fang DD, Wang B, Fu ZJ, Yan SL, Wang YG. Serum 25-hydroxyvitamin $D$ levels and peripheral neuropathy in patients with type 2 diabetes: a systematic review and meta-analysis. J Endocrinol Invest. 2015:38(5):513-8.

26. Boitard C, Cavaroc A, Sauvant J, Aubert A, Castanon N, Layé S, Ferreira G. Impairment of hippocampal-dependent memory induced by juvenile highfat diet intake is associated with enhanced hippocampal inflammation in rats. Brain Behav Immun. 2014;40:9-17.

27. Kaczmarczyk MM, Machaj AS, Chiu GS, Lawson MA, Gainey SJ, York JM, Meling DD, Martin SA, Kwakwa KA, Newman AF, et al. Methylphenidate prevents high-fat diet (HFD)-induced learning/memory impairment in juvenile mice. Psychoneuroendocrinology. 2013;38(9):1553-64.

28. Voss $U$, Sand E, Olde B, Ekblad E. Enteric neuropathy can be induced by high fat diet in vivo and palmitic acid exposure in vitro. PLoS One. 2013; 8(12):e81413.

29. Voss U, Turesson MF, Robaye B, Boeynaems JM, Olde B, Erlinge D, Ekblad E. The enteric nervous system of $\mathrm{P} 2 \mathrm{Y} 13$ receptor null mice is resistant against high-fat-diet- and palmitic-acid-induced neuronal loss. Purinergic Signal. 2014;10:455

30. Stenkamp-Strahm CM, Kappmeyer AJ, Schmalz JT, Gericke M, Balemba O. High-fat diet ingestion correlates with neuropathy in the duodenum myenteric plexus of obese mice with symptoms of type 2 diabetes. Cell Tissue Res. 2013:354(2):381-94.

31. Morin JP, Rodríguez-Durán LF, Guzmán-Ramos K, Perez-Cruz C, Ferreira G, Diaz-Cintra S, Pacheco-López G. Palatable Hyper-Caloric Foods Impact on Neuronal Plasticity. Front Behav Neurosci. 2017;11:19.

32. Eslick GD, Talley NJ. Prevalence and relationship between gastrointestinal symptoms among individuals of different body mass index: A populationbased study. Obes Res Clin Pract. 2016;10(2):143-50.

33. Wiltink J, Michal M, Wild PS, Zwiener I, Blettner M, Münzel T, Schulz A, Kirschner $Y$, Beutel ME. Associations between depression and different measures of obesity (BMI, WC, WHtR, WHR). BMC Psychiatry. 2013;13:223.

34. Furness JB, Callaghan BP, Rivera LR, Cho HJ. The enteric nervous system and gastrointestinal innervation: integrated local and central control. Adv Exp Med Biol. 2014;817:39-71.

35. Reeves PG, Nielsen FH, Fahey GC. AIN-93 purified diets for laboratory rodents: final report of the American Institute of Nutrition ad hoc writing committee on the reformulation of the AIN-76A rodent diet. J Nutr. 1993;123(11):1939-51.

36. Sand E, Themner-Persson A, Ekblad E. Corticotropin releasing factor-Distribution in rat intestine and role in neuroprotection. Regul Pept. 2011;166(1-3):68-75.

37. Voss U, Sand E, Hellstrom PM, Ekblad E. Glucagon-like peptides 1 and 2 and vasoactive intestinal peptide are neuroprotective on cultured and mast cell co-cultured rat myenteric neurons. BMC Gastroenterol. 2012;12:30.

38. Hoffstrom BG, Kaplan A, Letso R, Schmid RS, Turmel GJ, Lo DC, Stockwell BR. Inhibitors of protein disulfide isomerase suppress apoptosis induced by misfolded proteins. Nat Chem Biol. 2010;6(12):900-6.

39. Voss U, Turesson MF, Robaye B, Boeynaems J-M, Olde B, Erlinge D, Ekblad E. The enteric nervous system of $\mathrm{P} 2 \mathrm{Y} 13$ receptor null mice is resistant against high fat diet- and palmitic acid-induced neuronal loss. Purinergic Signal. 2014;10(3):455-64

40. Nezami BG, Mwangi SM, Lee JE, Jeppsson S, Anitha M, Yarandi SS, Farris AB, Srinivasan S. MicroRNA 375 Mediates Palmitate-Induced Enteric Neuronal Damage and High-Fat Diet-Induced Delayed Intestinal Transit in Mice. Gastroenterology. 2014;146(2):473-483.e473.

41. Ghaly S, Kaakoush NO, Lloyd F, McGonigle T, Mok D, Baird A, Klopcic B, Gordon L, Gorman S, Forest C, et al. High Dose Vitamin D supplementation alters faecal microbiome and predisposes mice to more severe colitis. Sci Rep. 2018;8(1):11511. 
42. Matsuda S, Kitagishi Y. Peroxisome proliferator-activated receptor and vitamin d receptor signaling pathways in cancer cells. Cancers (Basel). 2013;5(4):1261-70.

43. Ekwaru JP, Zwicker JD, Holick MF, Giovannucci E, Veugelers PJ. The importance of body weight for the dose response relationship of oral vitamin D supplementation and serum 25-hydroxyvitamin D in healthy volunteers. PLoS One. 2014;9(11):e111265.

44. Landrier JF, Marcotorchino J, Tourniaire F. Lipophilic Micronutrients and Adipose Tissue Biology. Nutrients. 2012;4(11):1622-49.

45. Guariguata L, Whiting DR, Hambleton I, Beagley J, Linnenkamp U, Shaw JE. Global estimates of diabetes prevalence for 2013 and projections for 2035 Diabetes Res Clin Pract. 2014;103(2):137-49.

46. Palacios C, Gonzalez L. Is vitamin D deficiency a major global public health problem? J Steroid Biochem Mol Biol. 2014;144 Pt A:138-45.

47. Eugene C, Yangha K. Vitamin D Decreases Adipocyte Lipid Storage and increases NAD-SIRT1 Pathway in 3T3-L1 Adipocytes. Nutrition. 2016; 32(6):702-8

48. Yin Y, Yu ZW, Xia M, Luo XQ, Lu XF, Ling WH. Vitamin D attenuates high fat diet-induced hepatic steatosis in rats by modulating lipid metabolism. Eur J Clin Invest. 2012;42(11):1189-96.

49. Berger J, Dorninger F, Forss-Petter S, Kunze M. Peroxisomes in brain development and function. Biochim Biophys Acta. 2016;1863(5):934-55.

50. Romano A, Koczwara JB, Gallelli CA, Vergara D, Micioni Di Bonaventura MV, Gaetani S, Giudetti AM. Fats for thoughts: An update on brain fatty acid metabolism. Int J Biochem Cell Biol. 2017:84:40-5.

51. Lee J, Wolfgang MJ. Metabolomic profiling reveals a role for CPT1c in neuronal oxidative metabolism. Bmc Biochem. 2012;13.

52. Sierra AY, Gratacos E, Carrasco P, Clotet J, Urena J, Serra D, Asins G, Hegardt FG, Casals N. CPT1C is localized in endoplasmic reticulum of neurons and has carnitine palmitoyltransferase activity. J Biol Chem. 2008;283(11):6878-85.

53. Huhtakangas JA, Olivera CJ, Bishop JE, Zanello LP, Norman AW. The vitamin $D$ receptor is present in caveolae-enriched plasma membranes and binds 1 alpha,25(OH)2-vitamin D3 in vivo and in vitro. Mol Endocrinol. 2004;18(11): 2660-71.

54. Wang Y, DeLuca HF. Is the vitamin d receptor found in muscle? BMC Biochem. 2012;13:23.

55. Castillo V, Oñate M, Woehlbier U, Rozas $P$, Andreu C, Medinas D, Valdés $P$, Osorio F, Mercado G, Vidal RL, et al. Functional Role of the Disulfide Isomerase ERp57 in Axonal Regeneration. PLoS One. 2015;10(9):e0136620.

56. Pendyala G, Ninemire C, Fox HS. Protective role for the disulfide isomerase PDIA3 in methamphetamine neurotoxicity. PLoS One. 2012;7(6):e38909.

57. Yamamoto E, Uchida T, Abe H, Taka H, Fujimura T, Komiya K, Hara A, Ogihara T, Fujitani Y, Ueno T, et al. Increased expression of ERp57/GRP58 is protective against pancreatic beta cell death caused by autophagic failure. Biochem Biophys Res Commun. 2014;453(1):19-24.

58. Zhang XQ, Pan Y, Yu CH, Xu CF, Xu L, Li YM, Chen WX. PDIA3 Knockdown Exacerbates Free Fatty Acid-Induced Hepatocyte Steatosis and Apoptosis. PLoS One. 2015;10(7):e0133882

59. Neunlist M, Rolli-Derkinderen M, Latorre R, Van Landeghem L, Coron E, Derkinderen P, De Giorgio R. Enteric glial cells: recent developments and future directions. Gastroenterology. 2014;147(6):1230-7.

60. Erbaş O, Solmaz V, Aksoy D, Yavaşoğlu A, Sağcan M, Taşkıran D. Cholecalciferol (vitamin D 3) improves cognitive dysfunction and reduces inflammation in a rat fatty liver model of metabolic syndrome. Life Sci. 2014;103(2):68-72.

61. Kheder R, Hobkirk J, Saeed Z, Janus J, Carroll S, Browning MJ, Stover C. Vitamin D3 supplementation of a high fat high sugar diet ameliorates prediabetic phenotype in female LDLR(-/-) and LDLR(+/+) mice. Immun Inflamm Dis. 2017;5(2):151-62.

62. Liu C, Bookout AL, Lee S, Sun K, Jia L, Lee C, Udit S, Deng Y, Scherer PE, Mangelsdorf DJ, et al. PPARY in vagal neurons regulates high-fat diet induced thermogenesis. Cell Metab. 2014;19(4):722-30.

63. Tomas J, Mulet C, Saffarian A, Cavin JB, Ducroc R, Regnault B, Kun Tan C, Duszka K, Burcelin R, Wahli W, et al. High-fat diet modifies the PPAR- $y$ pathway leading to disruption of microbial and physiological ecosystem in murine small intestine. Proc Natl Acad Sci U S A. 2016;113(40):E5934-43.

64. Dunn MF, Ramírez-Trujillo JA, Hernández-Lucas I. Major roles of isocitrate lyase and malate synthase in bacterial and fungal pathogenesis. Microbiology. 2009;155(Pt 10):3166-75.

65. Davis WL, Matthews JL, Goodman DB. Glyoxylate cycle in the rat liver: effect of vitamin D3 treatment. FASEB J. 1989;3(5):1651-5.
66. Davis WL, Goodman DB. Evidence for the glyoxylate cycle in human liver. Anat Rec. 1992;234(4):461-8.

67. Davis WL, Jones RG, Farmer GR, Cortinas E, Matthews JL, Goodman DB. The glyoxylate cycle in rat epiphyseal cartilage: the effect of vitamin-D3 on the activity of the enzymes isocitrate lyase and malate synthase. Bone. 1989;10(3):201-6.

68. Davis WL, Goodman DB, Crawford LA, Cooper OJ, Matthews JL. Hibernation activates glyoxylate cycle and gluconeogenesis in black bear brown adipose tissue. Biochim Biophys Acta. 1990;1051(3):276-8.

69. Kondrashov FA, Koonin EV, Morgunov IG, Finogenova TV, Kondrashova MN. Evolution of glyoxylate cycle enzymes in Metazoa: evidence of multiple horizontal transfer events and pseudogene formation. Biol Direct. 2006;1:31.

70. Song S. Can the glyoxylate pathway contribute to fat-induced hepatic insulin resistance? Med Hypotheses. 2000;54(5):739-47.

71. Popov VN, Igamberdiev AU, Schnarrenberger C, Volvenkin SV. Induction of glyoxylate cycle enzymes in rat liver upon food starvation. FEBS Lett. 1996; 390(3):258-60.

72. Song S. The role of increased liver triglyceride content: a culprit of diabetic hyperglycaemia? Diabetes Metab Res Rev. 2002;18(1):5-12.

73. Sand E, Voss U, Hammar O, Alm R, Nordin Fredrikson G, Ohlsson B, Ekblad E. Gonadotropin-releasing hormone analog buserelin causes neuronal loss in rat gastrointestinal tract. Cell Tissue Res. 2013;351(3):521-34.

74. Svensson D, Nebel D, Voss U, Ekblad E, Nilsson BO. Vitamin D-induced upregulation of human keratinocyte cathelicidin anti-microbial peptide expression involves retinoid X receptor a. Cell Tissue Res. 2016;366(2):353-62.

75. Orchard GE. Comparison of immunohistochemical labelling of melanocyte differentiation antibodies melan-A, tyrosinase and $\mathrm{HMB} 45$ with NKIC3 and S100 protein in the evaluation of benign naevi and malignant melanoma. Histochem J. 2000;32(8):475-81.
Ready to submit your research? Choose BMC and benefit from:

- fast, convenient online submission

- thorough peer review by experienced researchers in your field

- rapid publication on acceptance

- support for research data, including large and complex data types

- gold Open Access which fosters wider collaboration and increased citations

- maximum visibility for your research: over $100 \mathrm{M}$ website views per year

At BMC, research is always in progress.

Learn more biomedcentral.com/submissions 